\title{
The Resource Replenishment Function of Interest
}

By: Dustin B. Thoman, Jessi L. Smith, and Paul J. Silvia

Dustin B. Thoman, Jessi L. Smith, \& Paul J. Silvia (2011). The resource replenishment function of interest. Social Psychological and Personality Science, 2(6), 592-599.

Made available courtesy of Sage Publications: https://doi.org/10.1177/1948550611402521

***Reprinted with permission. No further reproduction is authorized without written permission from Sage Publications. This version of the document is not the version of record. Figures and/or pictures may be missing from this format of the document. ***

***Dustin B. Thoman, Jessi L. Smith, and Paul J. Silvia, The resource replenishment function of interest, Social Psychological and Personality Science (Volume 2, Number 6) pp. 592-599. Copyright $@ 2011$ The Authors. Reprinted by permission pf SAGE Publications***

\begin{abstract}
:
Interest is a positive emotion associated with increased approach motivation, effort, attention, and persistence. Although experiencing interest promotes behaviors that demand cognitive resources, interest is as a coping resource in frustrating learning situations and is central to selfregulation and sustained motivation. Positive affect, in general, tends to replenish resources, but based on the functions of interest and what interest promotes we suggest that interest, in particular, promotes greater resource replenishment. Across three experiments, experiencing interest during activity engagement (Studies $1 \& 2$ ), even when interest is activated via priming (Study 3), caused greater effort and persistence in subsequent tasks than did positive affect. This effect occurred only when participants' psychological resources were previously depleted (Study 1). Paradoxically, engaging an interesting task replenished resources (vs. positive and neutral tasks) even though the interesting task was more complex and required more effort.
\end{abstract}

Keywords: interest | resource depletion | motivation | positive affect | emotion | self-regulation

Article:

When coming home tired from a long day it seems more difficult to dive into a tedious task than to do something interesting first, even if the interesting thing requires the same (if not more) energy and effort. For example, when tired, although we can force ourselves to focus attention on an uninteresting grading task, we might first read a new but complex paper that we are interested in before starting the grading. Even though the grading is relatively simpler cognitively, it can be easier to maintain the energy and motivation to persist on this boring task if we do something interesting first. Students, too, seem to understand that when feeling depleted they can regain energy for studying uninteresting material if they do something interesting as study breaks, even though the interesting task may be just as cognitively complex. So, when our 
resources are depleted, why might first engaging an interesting task make it easier to exert effort toward another task?

Positive affect can replenish resources and motivate subsequent task engagement (e.g., Tice, Baumeister, Shmueli, \& Muraven, 2007). Both theory and research suggest that positive emotions, and positive affect more generally, facilitate psychological resources (e.g., Aspinwall, 1998; Fredrickson, 2001; Thayer, 1989), and experiencing positive affect restores depleted resources better than sad or neutral affect (Tice et al., 2007). We propose that one functional property of the emotion interest is to harness resources needed to engage a task, and if these resources are depleted, experiencing interest will aid their replenishment, above and beyond positive affect. Emotion research suggests that interest's functions are unique among the positive emotions, particularly with regard to its promotion of motivation (Silvia, 2008).

\section{What is Interest? Defining its Functions}

Functional approaches to interest suggest that it is a positive emotion strongly associated with approach motivation (Fredrickson, 1998; Izard, 1977; Silvia, 2008; Tomkins, 1962). Globally, interest fosters the development of competence and skills (Berlyne, 1978; Izard \& Ackerman, 2000) by motivating exploration, focused attention, and persistence (Berlyne, 1966; Csikszentmihalyi, 1978; Fredrickson, 2001; Schiefele, Krapp, \& Winteler, 1992). Apart from the obvious value of motivating exploration and learning, interest builds skills by serving as an approach-oriented counterweight to avoidance-oriented feelings of frustration, boredom, and confusion (Katz, Assor, Kanat-Maymon, \& Bereby-Meyer, 2006; Renninger, 2000; Silvia, 2010). People seem to have a lay theory of interest as a motivational resource: when there's a good reason to persist in a boring activity, people will use interest-enhancing strategies to increase their motivation (Sansone, Wier, Harpster, \& Morgan, 1992; Smith, Wagaman, \& Handley, 2009). For these reasons, interest is central to intrinsic motivation and self-regulation (e.g., Harackiewicz \& Hulleman, 2010; Hidi \& Ainley, 2008; Sansone \& Thoman, 2005; Sansone, Thoman, \& Smith, 2010; Silvia, 2008).

Interest is distinct from general positive affect and from other positive emotions, such as happiness. From a functional perspective, interest and happiness motivate different actions. Among other things, happiness builds attachments to familiar sources of reward and to factors that promote progress toward valued goals. Interest, in contrast, motivates engaging with things that are new, unfamiliar, and potentially unrewarding. Many studies have shown a basic difference in the causes of happiness and interest: familiar and simple things bring about enjoyment, but novel, complex, and unusual things bring about interest (Kashdan \& Silvia, 2009; Turner \& Silvia, 2006). The different motivational roles are also apparent in their consequences for action. In particular, interest predicts exploratory behavior more strongly than enjoyment does. Early studies on exploration showed that paired-choice exploration (e.g., choosing which of two images to view) was driven more strongly by an image's interestingness than pleasingness (Berlyne, 1963; Berlyne \& Crozier, 1971). Similar studies of open-ended exploration (e.g., choosing how long to explore something) found that interest explained more variance than enjoyment in both viewing time (an average of 44\% vs. 14\%; Berlyne, 1974) and listening time (78\% vs. 10\%; Crozier, 1974).Overall, interest is more strongly tied than enjoyment is to engaging with and exploring new things. 


\section{Why Interest Replenishes Resources}

Unlike the positive emotions that promote social bonding and attraction, psychological resources are required for all actions that interest promotes. If interest necessarily uses cognitive resources by directing resource-draining activities, when depleted, people would be either unable to experience interest or interest would fail in its functions. But if interest also replenishes resources, it becomes a much more adaptive emotion by being able to promote approach motivation, exploration, and attention across a wider range of situations. Conversely, if interest doesn't replenish resources, its adaptive functions could be realized only when people had enough available resources. In this case, the functional value of interest would be limited, which is inconsistent with models that emphasize its importance for sustained motivation and learning (Katz et al., 2006; Sansone \& Thoman, 2005). Therefore, based on the psychological functions of interest, we hypothesized that one function of interest is to replenish previously depleted psychological resources that can promote motivation on subsequent tasks.

A number of mechanisms could explain this effect. Like positive affect, interest may energize self-regulatory resources and counteract resource depletion directly (Baumeister et al., 1998) or create physiological energy (Fredrickson, 2001; Thayer, 1989). Alternatively, greater feelings of competence following the experience of interest could facilitate energy available to the self (Ryan \& Deci, 2008). Yet another possibility is that appraisals associated with interest (Silvia, 2006) become activated during the interest experience, and are then more likely to be applied to subsequent activities. We explore some of these possibilities in the present research.

\section{The Present Research}

Three experiments tested the hypothesis that interest replenishes resources more so than positive affect. In each study, we depleted participants' resources, manipulated their emotional experience, and then measured their resources via persistence on a subsequent task. This paradigm is consistent with previous resource depletion research (e.g., Baumeister, Bratslavsky, Muraven, \& Tice, 1998; Muraven, Tice, \& Baumeister, 1998; Tice et al., 2007). Across the studies we varied how resources were depleted and measured and how emotional states were manipulated.

Because interest is usually experienced in the context of activity engagement (Hidi, 1990; Krapp, 2002), we first developed a manipulation that differentially affected interest and positive affect (Study 1). Most manipulations of positive affect are confounded with interest, such as having participants watch a comedy video (Baumeister et al., 1998; Tice et al., 2007). Once we created these manipulations, we examined whether experiencing interest would increase persistence on a subsequent task only when participants' resources had been depleted (Study 1) and whether, paradoxically, experiencing interest following resource depletion would promote greater resources even when the interesting task is more complex and effortful (Study 2).

In addition, although interest is typically experienced in the context of activity engagement, we predicted that interest should promote resource replenishment even when it is activated cognitively, such as through priming and recall (Martin, 1990; Zemack-Rugar, 
Bettman, \& Fitzsimons, 2007). Testing whether interest predicts resource replenishment in such contexts is important for demonstrating that it is the emotion of interest that predicts resource replenishment, not the interest-supporting materials themselves (Hidi, 1990). Study 3 thus tested whether interest replenishes resources when activated via a cognitive manipulation. Finally, across the studies we explored possible explanations for this effect, including increased feelings of competence and priming of interest's appraisals.

\section{Study 1}

The purpose of Study 1 was threefold: (1) to provide evidence for our research materials and manipulation for use in Study 2; (2) to test whether engaging in an interesting task following resource depletion would influence participants' subsequent motivational resources; and (3) to explore the mediational role of feelings of competence. We predicted that, following resource depletion, people in the interest condition would show the most self-regulatory resource replenishment by persisting on an unrelated task, but that there would be no effect of condition for participants who were not previously depleted.

\section{Participants}

Participants were 147 undergraduate students (47\% Female; 96\% White, 2\% Asian, 2\% Native American; $M$ age $=20.07$ ) from introductory psychology who participated for course credit. Participants were recruited for a "two-part" study on "Mindfulness and Schematic Representation.”

\section{Procedure and Manipulations}

Through random assignment, half of the participants first completed a lengthy battery of surveys assessing individual differences, and half completed the survey battery at the end of the study $^{1}$. Participants were told that there were many surveys to complete and we needed participants to get through them all if possible, but that they could choose when to stop. Having participants work on an undesired but free choice task is similar to past work that forced people to continue something they dislike (Baumeister, DeWall, Ciarocco, \& Twenge, 2005) or find frustrating (Tice et al., 2007). Survey order was our manipulation of resource depletion. The survey was administered via computer. No one opted out or finished the entire survey-all participants were stopped after $30 \mathrm{~min}$.

Either before or after completing the survey, participants were randomly assigned to perform one of three 10 minute "cognitive tasks related to visual recognition, search and representation," which served as the emotion manipulation. All participants were given a notebook that contained the same 10 mystery passages (Thoman \& Sansone, 2010). In the "interest" condition, participants were asked to read and solve each mystery. In the "positive affect" condition participants were asked to search for all of the underlined words (which were all positive in nature, e.g., butterfly, beautiful, music) and to list them on a subsequent page and write their association with each word. The positive words and manipulation of positive affect were taken from Fishbach and Labroo (2007). Those in the "neutral" condition were asked to search for all of the underlined words (which were all neutral, e.g., when, the, into, continued, 
does) and to list them on a subsequent page, again modeled after Fishbach and Labroo (2007). In all, participants were randomly assigned to one of 6 conditions in a 2 (depletion vs. no depletion) $\mathrm{X} 3$ (interest vs. positive vs. neutral) between-subjects design.

Following the emotion manipulation, participants completed an "evaluation" of the task they had just completed. Specifically, participants completed several manipulation checks including self-reported feelings of positive and negative affect (assessed using the PANAS, Watson, Clark \& Tellegen, 1988), depletion (4 items $(\alpha=.88)$, e.g., "I felt tired after doing this task"), and amount of effort exerted on the task ("This task took a lot of effort to complete"). Participants also completed items to assess ratings of interest in the task (6 items $(\alpha=.91)$, e.g., "I would describe this task as very interesting") and perceived competence (3 items $(\alpha=.90)$, e.g., "I felt that I did the task well”). PANAS items were rated on a 1 to 5 scale; all other items were rated on a 1 (strongly disagree) to 7 (strongly agree) Likert scale and were modeled after past research (e.g., Smith, Sansone, \& White, 2007). Finally, to assess persistence on an unrelated task, participants were given a Thematic Aperception Picture (of two women in lab coats) and asked to "write a complete story about the picture you see above." The total number of words written was our measure of persistence. ${ }^{2}$ Persistence on tasks, games, or puzzles is a common index of resource replenishment (e.g., Baumeister et al., 1998; Muraven, \& Slessareva, 2003; Tice et al., 2007).

\section{Results}

Manipulation checks. We first tested whether completing the survey battery before the task resulted in greater feelings of depletion. This was confirmed by a main effect of survey order on ratings of depletion, $\left.F(1,140)=17.44, p<.05, \eta_{\mathrm{p}}{ }^{2}=.11\right)$. Participants who completed the survey battery before the task reported feeling significantly more depleted $(M=4.75, S E=$ $.54)$ than those who completed the task first $(M=3.75, S E=.56)$.

We next tested whether the emotion manipulation (i.e., instructions for the mystery story task) was successful, and this was confirmed by a main effect of condition on positive affect $\left(F(2,102)=2.99, p=.05, \eta_{\mathrm{p}}^{2}=.06\right)$ and interest in the task $\left(F(2,139)=9.65, p<.05, \eta_{\mathrm{p}}{ }^{2}=.12\right)$. Follow-up tests showed participants in the positive affect condition reported significantly higher positive affect $(M=35.61, S E=1.72)$ compared to participants in the neutral $(M=30.14, S E=$ $1.76, p<.05)$ and interesting conditions $(M=30.67, S E=1.85, p=.053)$, which didn't differ from each other $(p>.10)$. Likewise, participants in the interesting condition reported significantly more interest in the task $(M=4.53, S E=1.21)$ than participants in the neutral $(M=$ 3.30, $S E=1.18, p<.05)$ and positive conditions $(M=3.75, S E=1.15, p<.05)$, which didn't differ from each other $(p>.10)$. The interesting task $(M=4.71, S E=.24)$ was also perceived as requiring significantly more effort than the other tasks (neutral $M=2.39, S E=.24$; positive $M=$ $2.49, S E=.23), F(2,141)=29.92, p<.05, \eta_{\mathrm{p}}^{2}=.30$.

Effects of depletion and emotion on motivation. Because the manipulation checks supported the separate manipulations of interest and positive affect, we next examined whether participants would exert differential persistence on a subsequent task depending on prior depletion. We conducted a 2 (depletion vs. no depletion) X 3 (interest vs. positive vs. neutral) between-subjects ANOVA predicting persistence on the writing task. Results showed significant 
main effects of survey order $\left(F(1,124)=8.54, p=.004, \eta_{\mathrm{p}}{ }^{2}=.06\right)$ and emotion manipulation $\left(F(2,124)=6.45, p=.002, \eta_{\mathrm{p}}{ }^{2}=.09\right)$, as well as a significant interaction, $F(2,124)=3.01, p=$ $.05, \eta_{\mathrm{p}}{ }^{2}=.05$. Simple effects tests suggested that emotion condition only predicted persistence on the writing task for those who were depleted, $F(2,124)=9.23, p<.001$. As shown in Figure 1 , when depleted, participants in the interest condition $(M=121.58, S E=12.01)$ wrote significantly more compared to the positive condition $(M=86.00, S E=12.54, p<.05)$, and both of these conditions wrote more than those in the neutral condition $(M=48.58, S E=12.01, p<.05)$. There were no significant differences between conditions when participants were not previously depleted $(F(2,124)=1.00, p=.37)$.

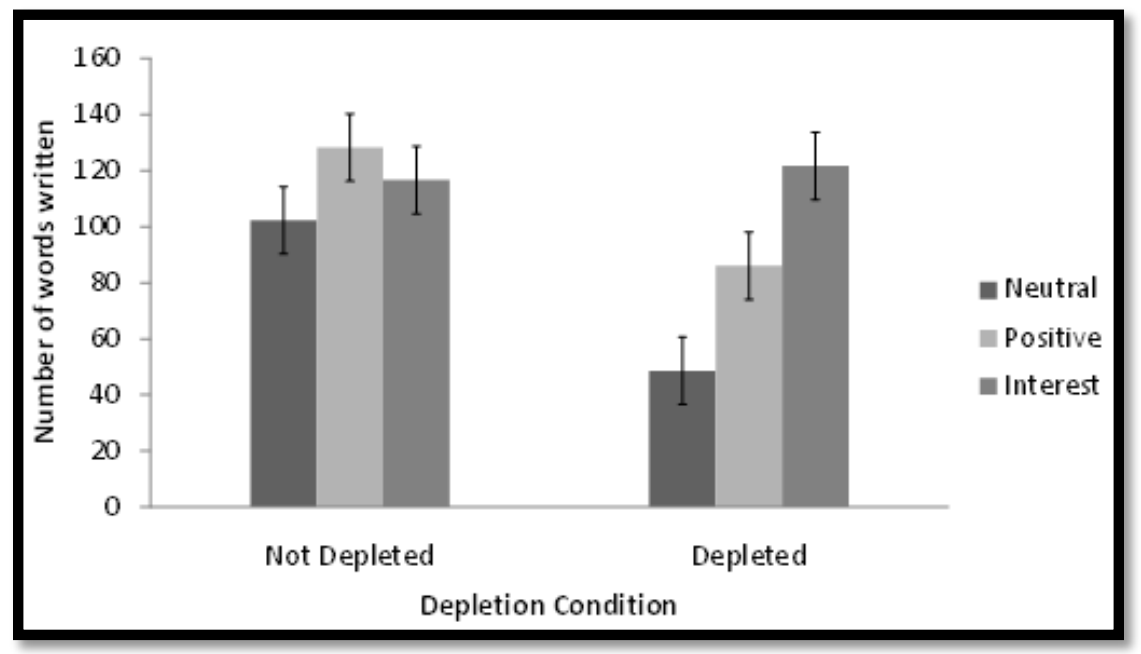

Figure 1. Interaction of depletion and emotion conditions predicting task effort, Study 1.

To test whether motivation was greater following the interesting task because of increased feelings of competence, we repeated the ANOVA predicting ratings of competence. Although results showed a significant main effect of the emotion manipulation $(F(2,124)=$ 23.83, $\left.p<.001, \eta_{\mathrm{p}}{ }^{2}=.31\right)$, participants who worked on the interesting task actually felt less competent $(M=10.80, S E=.50)$ than those in the positive $(M=14.48, S E=.50 p=.001)$ or neutral $(M=15.37, S E=.50, p=.001)$ conditions, ruling out the possibility that interest led to greater motivation by increasing feelings of competence. Results showed no main effect of order or interaction $(p s>.10)$.

\section{Discussion}

The first goal of Study 1 was to examine the validity of our new emotion manipulation. The instructions for the mystery story task successfully manipulated interest and positive affect as expected. These results suggest that the materials and instructions are useful for separately manipulating interest and positive affect. The second goal of Study 1 was to test whether interest would increase persistence on the subsequent task when participants were depleted. Results demonstrated resource replenishment effects, both for positive affect and interest. First, replicating past work (Tice et al., 2007), experiencing positive affect (vs. neutral) led to greater persistence following resource depletion. Importantly, experiencing interest - even when it required more effort - replenished motivation more than positive affect did. Feelings of competence didn't seem to explain this effect. These differences in persistence can be attributed 
to the resource replenishment properties of interest and positive affect because there were no differences when participants weren’t depleted.

\section{Study 2}

The aim of Study 2 was to replicate the finding that engaging in an interesting task would increase motivational resources of previously depleted participants, but with standard methods of depleting and measuring resources. Because finding that the most effortful (but interesting) task increased resources seems paradoxical, we expanded the assessment of task experience to include ratings of both effort and task complexity. We predicted that those in the interest condition would describe the interesting task as effortful and complex but also demonstrate the greatest resource replenishment by persisting longer on an unrelated task. We first depleted participants using a Stroop task (Schmeichel, Vohs, \& Baumeister, 2003) and then asked them to work on the interesting, happy, or neutral activities used in Study 1. We measured how long participants subsequently persisted on a difficult anagram task, a common assessment of selfregulatory resources (Baumeister et al., 1998). Participants also completed ratings of competence and reported their appraisals of the anagrams task. In this way, we tested if the null results for competence would replicate and explored if increased persistence was due to effects of the emotion manipulation on appraisals of the anagrams task.

\section{Participants}

Participants were 76 undergraduate students ${ }^{3}$ from introductory psychology, who participated for course credit, recruited for a study on "cognitive evaluation and recognition processes" that required unrelated tasks.

\section{Procedure}

First, all participants worked on a Stroop task for 15 minutes with the goals of maximizing both accuracy and speed. Next, participants were randomly assigned to one of the three conditions (interest, positive, or neutral) of the mystery story task used in Study 1. Afterward, participants were asked the same 3 competence items $(\alpha=.86)$ used in Study 1 , as well as 3 items ( $\alpha=$.87) about the task's complexity (e.g., "I would describe this task as simple" (reversed)), taken from Silvia (2005), and how much effort the task took ("This task took a lot of effort to complete") using a scale from 1 (strongly disagree) to 7 (strongly agree). Finally, all participants worked on a one-page anagrams task, consisting of difficult 7-letter anagrams, and were instructed to work for as long as they could. Time spent on the anagrams was the measure of persistence (cf. Schmeichel et al., 2003). Participants were stopped after 20 minutes if they had not already quit. Following the anagrams task, participants completed an identical questionnaire as they had completed for the mystery story task, to rate their perceptions of the anagrams task.

\section{Results and Discussion}

Ratings of task complexity and effort by condition were examined with separate ANOVAs. As predicted, the interesting task was rated as more complex $(M=4.29, S E=.54)$ 
than both the positive $(M=3.49, S E=.53, p<.05)$ and neutral tasks $(M=3.33, S E=.47, p<$ $.05), F(2,73)=24.87, p<.05, \eta_{\mathrm{p}}^{2}=.51$. The interesting task also required more effort to complete $(M=5.25, S E=.35)$ than both the positive $(M=3.12, S E=.34, p<.05)$ and neutral tasks $(M=2.74, S E=.27, p<.05), F(2,73)=17.59, p<.05, \eta_{\mathrm{p}}^{2}=.32$.

Testing the primary hypothesis, an ANOVA predicting persistence on the anagram task was significant, $F(2,73)=8.90, p<.05, \eta_{\mathrm{p}}{ }^{2}=.19$. As illustrated in Figure 2, participants who worked on the interesting task $(M=10.36, S E=.83)$ persisted longer than those in the positive condition $(M=7.86, S E=1.03, p<.05)$; both persisted longer than those in the neutral condition $(M=5.45, S E=.58, p s<.05)$.

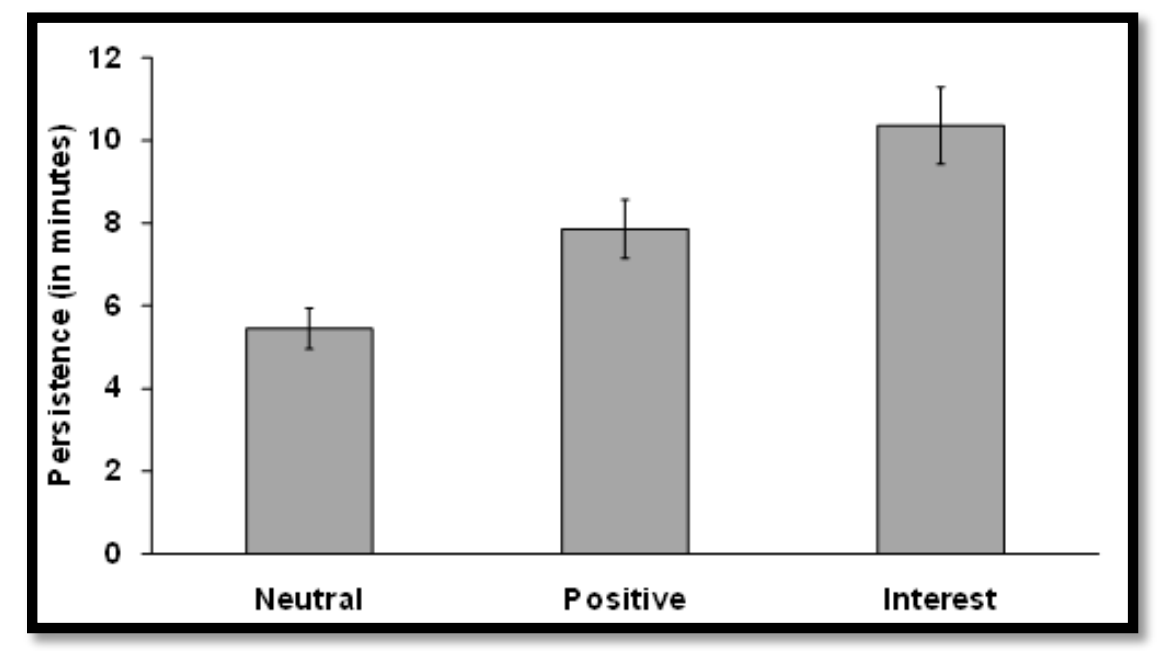

Figure 2. Persistence by emotions condition, Study 2.

As in Study 1, participants reported lower competence following the interesting task $(M=$ $11.21, S E=.62)$ than both the positive $(M=17.80, S E=.61, p<.05)$ and neutral tasks $(M=$ $18.07, S E=.58, p<.05), F(2,73)=40.39, p<.001, \eta_{\mathrm{p}}^{2}=.52$. Finally, results showed no significant differences between conditions for ratings of task interest $(F(2,73)=1.05, p=.35$, $\left.\eta_{\mathrm{p}}^{2}=.03\right)$ or complexity $\left(F(2,73)=0.74, p=.48, \eta_{\mathrm{p}}^{2}=.02\right)$.

Paradoxically, depleted participants who worked on the most complex task that required the most effort and led to the lowest feelings of competence subsequently persisted longer on a difficult anagram task than those who worked on simpler and easier tasks because, even though it required more effort, the task was interesting. Among the simpler tasks, those in the positive affect condition persisted longer than those in the neutral condition, again replicating Tice et al. (2007). Finding that participants' ratings of interestingness and complexity of the anagram task did not differ by condition suggests that the effect of interest on subsequent motivation was not due to activated appraisals of interest carrying over to the subsequent task.

\section{Study 3}

Study 3 examined whether a cognitive operationalization of interest would predict resource replenishment. Although typically experienced in the context of activity engagement, interest should promote resource replenishment regardless of how it is activated. Testing this 
hypothesis is important for demonstrating that resource replenishment is a function of interest itself and not from interest-stimulating activities (Hidi, 1990). All participants were initially depleted (using a Stroop task) and then asked to write about an interesting, positive, or neutral memory. Participants then returned to the Stroop task, and we measured how long they persisted. We predicted that those in the interest condition would persist longer upon returning to the Stroop task than those in the positive and neutral conditions.

\section{Participants}

Participants were 123 undergraduate students (69\% Female; 34\% White, 30\% Latino, 26\% Asian, 4\% African American; $M$ age = 19.80; $S D=2.60$ ) from introductory psychology who participated for course credit.

\section{Procedure}

Participants received the same cover story as Study 2 and worked first on the Stroop task for 15 minutes to deplete resources. Next, participants were randomly assigned to one of three 10-minute writing tasks, which served as the emotion manipulation (modeled after Martin, 1990). For all conditions, the instructions included: "Please describe the experience in as much detail as possible, including as much as you can about what you were thinking and feeling. Remember to describe the event and experience as thoroughly as possible from your memory." Those in the neutral affect condition wrote about their "daily morning routine." Those in the positive affect condition wrote about "an event that occurred any time in the last few years when you remember feeling particularly positive. The event can be any time when you experienced a great deal of happiness or were in an especially great mood.” Finally, those in the interest condition wrote about "an event that occurred any time in the last few years when you remember feeling particularly interested in something. The event can be any time when you experienced a great deal of interest, which is experienced in both thoughts and feelings.”

Finally, participants worked on the Stroop again, but were this time instructed to work for as long as they could (Schmeichel et al., 2003). We recorded how long they persisted on this second Stroop task (in minutes).

To ensure that the writing manipulation primed the intended emotions, we coded responses for the total number of words and the frequency of specific emotion words. We counted how often participants used interesting (or related words, e.g., interested, fascinating), happy (or related words, e.g., happiness), and general positive affect or mood descriptions (e.g., enjoy, feel good). Lastly, we coded (yes or no) for whether the description contained any competence-related theme.

\section{Results and Discussion}

Manipulation check. ANOVAs showed no differences between emotion conditions in the number of words written, $(p=.17)$. As expected, those asked to write about interesting experiences $(M=2.32, S E=.27)$ wrote interesting more often than those who wrote about positive $(M=0.09, S E=.05)$ or neutral experiences $(M=0.02, S E=.02), F(2,131)=70.76, p<$ 
.01. Those who wrote about positive experiences $(M=3.44, S E=.39)$ wrote happy more often than those who wrote about interesting experiences $(M=0.20, S E=.09)$, and no participants wrote happy in the neutral condition $(F(2,131)=73.47, p<.01)$. Similarly, those in the positive condition $(M=1.67, S E=.31)$ wrote about positive affect more often than those in the interesting $(M=0.66, S E=.15)$ or neutral conditions $(M=0.12, S E=.06), F(2,131)=27.49, p$ $<.01$. No participants in the neutral condition wrote about competence themes, and there was no difference between how often competence themes were described by those in the interest $(M=$ $0.20, S E=.06)$ and positive conditions $(M=0.30, S E=.07), p=.20$.

Predicting persistence. An ANOVA predicting persistence from experimental group membership was significant, $F(2,120)=3.40, p<.05, \eta_{\mathrm{p}}{ }^{2}=.05$. As shown in Figure 3, follow-up comparisons demonstrated that participants who wrote about interest experiences $(M=8.06, S E$ $=.62)$ persisted longer than those who wrote about positive experiences $(M=6.01, S E=.61, p<$ $.05)$ or their daily routine $(M=6.21, S E=.58, p<.05)$, which were not significantly different $(p$ $>$.10).

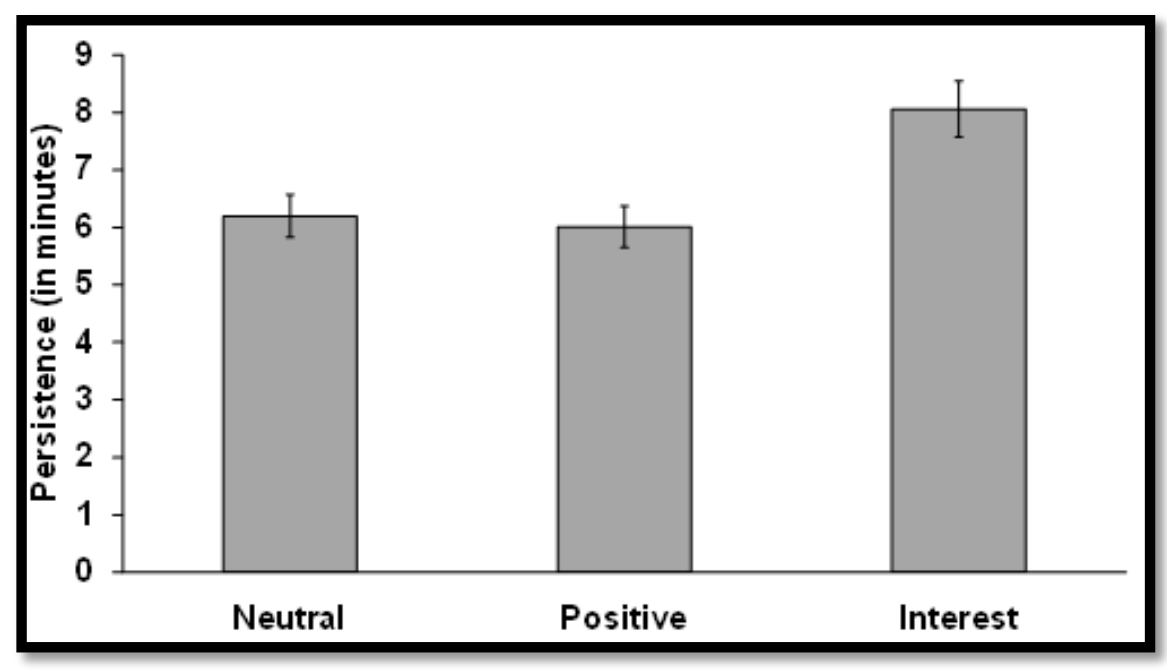

Figure 3. Persistence by emotion condition, Study 3

As predicted, resource-depleted participants who wrote about an interesting memory persisted longer when they returned to the activity that initially depleted them than those who wrote about positive or neutral memories. Despite using a relatively weak manipulation of emotion, these results further support the hypothesis that interest replenishes depleted resources more so than positive affect. People who wrote about positive memories didn't persist longer than those in the neutral condition, failing to replicate differences found by Tice et al. (2007) and Studies 1 and 2, probably because the cognitive manipulation was weaker than the activity manipulations used in the prior two experiments.

\section{General Discussion}

Across three studies, interest replenished resources more so than positive affect. This finding emerged when interest was activated during activity engagement (Studies 1 \& 2) and memory recall (Study 3). Those who experienced interest (vs. positive or neutral affect) 
demonstrated greater persistence both on subsequent unrelated tasks (Studies 1 \& 2) and upon returning to the originally depleting task (Study 3). This effect was found only when participants were previously depleted (Study 1), and thus cannot be attributed to the emotions without the context of psychological depletion.

The interesting activity used in Studies 1 and 2 was rated as more complex and required more effort than the other activities, which leads to the seemingly paradoxical conclusion that although the interesting task required more resources, it also made resources more available for subsequent tasks. Motivation for a task can be promoted when interested learning feels less effortful (e.g., Shirey \& Reynolds, 1988) or when an uninteresting task is strategically made more interesting (e.g., Sansone \& Thoman, 2005), but the present studies suggest that the psychological resources harnessed by interest also influence motivation toward unrelated tasks. Interest, therefore, is not only an important motivational variable for specific person-activity contexts; interest replenishes motivational resources that can be applied beyond the context sparked it.

The finding that interest promotes resource replenishment greater than positive affect is consistent with theory and research that suggests positive affect promotes psychological resources (e.g., Aspinwall, 1998; Fredrickson, 1998; Tice et al., 2007). Indeed, Studies 1 and 2 supported the resource building properties of positive affect, as positive affect replenished resources greater than the neutral activity. Only in Study 3, where we used a relatively weak manipulation of positive affect, were there no significant differences between the positive and neutral conditions. Our conclusions extend this work by suggesting that not all positive emotions are equal in their ability to promote resource replenishment. Interest is a positive emotion closely linked to motivation, and the actions that interest promotes (e.g., attention, exploration, consolidation) require cognitive resources to a greater extent than the actions, for example, that happiness promotes (e.g., attachment to rewarding people, places, and things), making resource replenishment a particularly adaptive property for interest. Without this function, interest could only promote motivation in circumstances when individuals had enough psychological resources.

Why does this work? We primarily drew from theory and research on psychological and physiological benefits of interest as a positive emotion for generating our resource replenishment explanation of how interest promotes subsequent motivation. However, we cannot be sure that interest (or positive affect) actually replenished the resources that had been depleted, as opposed to making participants more willing or motivated to persist on the subsequent task through another mechanism. We explored alternative possible mechanisms of increased competence (in all studies) and priming of interest appraisals (Study 2), but results failed to support these explanations. Indeed, research has raised questions about the broader mechanisms of selfregulatory strength and energy proposed in the ego depletion model (Muraven et al., 1998), and some of these interpretations may explain the present data as well. Plausible alternative mechanisms include the energizing effects of psychological need fulfillment (Ryan \& Deci, 2008), interest leading to greater self-awareness (Alberts, Martijn, \& de Vries, 2011) or priming persistence (Alberts, Martijn, Greb, Merckelbach, \& de Vries, 2007), and participants reciprocating the experimenter with effort following an interesting task. Elucidating the process by which interest promotes motivation and counteracts depletion, therefore, remains an intriguing problem for future research. 


\section{Declaration of Conflicting Interests}

The author(s) declared no potential conflicts of interests with respect to the authorship and/or publication of this article.

\section{Financial Disclosure/Funding}

The author(s) received no financial support for the research and/or authorship of this article.

\section{Notes}

1. Participants in the non-depletion condition completed the survey battery at the end because the surveys were used for other research.

2. We used the number of words written, not time spent on the task, as the measure of effort because participants were run in groups and started the task at different times. It was thus easier to accurately count text length than time spent writing.

3. A programming error prevented the saving of the demographic data that participants reported. This sample was recruited from the same pool as Study 3 and thus has similar demographic features.

Corresponding Author: Dustin B. Thoman, California State University, 1250 Bellflower Blvd, Long Beach, CA 90840, USA Email: dthoman@csulb.edu

\section{References}

Aspinwall, L. G. (1998). Rethinking the role of positive affect in self-regulation. Motivation and Emotion, 22, 1-32. doi: 10.1023/A:1023080224401

Baumeister, R. F., Bratslavsky, E., Muraven, M., \& Tice, D.M. (1998). Ego-depletion: Is the active self a limited resource? Journal of Personality and Social Psychology, 74, 12521265. doi: 10.1037/0022-3514.74.5.1252

Baumeister, R. F., DeWall, C., Ciarocco, N. J., \& Twenge, J. M. (2005). Social exclusion impairs self-regulation. Journal of Personality and Social Psychology, 88, 589-604. doi: 10.1037/0022-3514.88.4.589

Berlyne, D. E. (1963). Complexity and incongruity variables as determinants of exploratory choice and evaluative ratings. Canadian Journal of Psychology, 17, 274-290.

Berlyne, D. E. (1966). Curiosity and exploration. Science, 153, 25-33.

Berlyne, D. E. (1974). Verbal and exploratory responses to visual patterns varying in uncertainty and in redundancy. In D. E. Berlyne (Ed.) Studies in the new experimental aesthetics (pp. 121-158). Washington, DC: Hemisphere. 
Berlyne, D. E., \& Crozier, J. B. (1971). Effects of complexity and prechoice stimulation on exploratory choice. Perception and Psychophysics, 10, 242-246.

Berlyne, D. E. (1978). Curiosity and learning. Motivation and Emotion, 2, 97-175.

Crozier, J. B. (1974). Verbal and exploratory responses to sound sequences varying in uncertainty level. In D. E. Berlyne (Ed.) Studies in the new experimental aesthetics (pp. 27-90). Washington, DC: Hemisphere.

Csikszentmihalyi, M. (1978). Intrinsic rewards and emergent motivation. In M. R. Lepper \& D. Greene (Eds.), The hidden costs of reward (pp. 205-216). Hillsdale, NJ: Erlbaum.

Fishbach, A., \& Labroo, A.A. (2007). Be better or be merry: How mood affects self-control. Journal of Personality and Social Psychology, 93, 158-173. doi: 10.1037/00223514.93.2.158

Fredrickson, B. L. (1998). What good are positive emotions? Review of General Psychology, 2, 300-319. doi: 10.1037/1089-2680.2.3.300

Fredrickson, B. L. (2001). The role of positive emotions in positive psychology: The broadenand-build theory of positive emotions. American Psychologist, 56, 218-226. doi: 10.1037/0003-066X.56.3.218

Harackiewicz, J. M., \& Hulleman, C. S. (2010). The importance of interest: The role of achievement goals and task values in promoting the development of interest. Social and Personality Psychology Compass, 4, 42-52. doi:10.1111/j.1751-9004.2009.00207.x

Hidi, S. (1990). Interest and its contribution as a mental resource for learning. Review of Educational Research, 60, 549-571. doi: 10.2307/1170506

Hidi, S., \& Ainley, M. (2008). Interest and self-regulation: Relationships between two variables that influence learning. In D.H. Schunk \& B.J. Zimmerman (Eds.) Motivation and selfregulated learning: Theory, research, and applications. Mahwah, NJ: Lawrence Erlbaum and Associates.

Hidi, S., \& Renninger, K. A. (2006). The four-phase model of interest development. Educational Psychologist, 41, 111-127. doi: 10.1207/s15326985ep4102_4

Izard, C. E. (1977). Human emotions. New York: Plenum Press.

Izard, C. E. \& Ackerman, B. P. (2000). Motivational, organizational, and regulatory functions of discrete emotions. In M. Lewis \& J.M. Haviland-Jones (Eds.) Handbook of emotions ( $2^{\text {nd }}$ ed., pp. 253-264). New York: Guilford Press. 
Kashdan, T. B., \& Silvia, P. J. (2009). Curiosity and interest: The benefits of thriving on novelty and challenge. In C. R. Snyder \& S. J. Lopez (Ed.), Handbook of positive psychology (2nd ed., pp. 367-374). New York: Oxford University Press.

Katz, I., Assor, A., Kanat-Maymon, Y., \& Bereby-Meyer, Y. (2006). Interest as a motivational resource: Feedback and gender matter, but interest makes the difference. Social Psychology of Education, 9, 27-42. doi: 10.1007/s11218-005-2863-7

Krapp, A. (2002). Interest and human development during adolescence: An educationalpsychological approach. In J. Heckhausen (Ed.) Motivational psychology of human development: Developing motivation and motivating development (pp. 109-129). New York: Elsevier Science.

Martin, M. (1990). On the induction of mood. Clinical Psychology Review, 10, 669-697. doi: 10.1016/0272-7358(90)90075-L

Muraven, M., \& Slessareva, E. (2003). Mechanisms of self-control failure: Motivation and limited resources. Personality and Social Psychology Bulletin, 29, 894-906. doi: 10.1177/0146167203029007008

Muraven, M., Tice, D. M., \& Baumeister, R. F. (1998). Self-control as a limited resource: Regulatory depletion patterns. Journal of Personality and Social Psychology, 74, 774789. doi: 10.1037/0022-3514.74.3.774

Reeve, J. (1989). The interest-enjoyment distinction in intrinsic motivation. Motivation and Emotion, 13, 83-103. doi: 10.1007/BF00992956

Renninger, K. A. (2000). Individual interest and its implications for understanding intrinsic motivation. In C. Sansone \& J. M. Harackiewicz (Eds.), Intrinsic and extrinsic motivation: The search for optimal motivation and performance (pp. 375-407). San Diego, CA: Academic.

Ryan, R. M., \& Deci, E. L. (2008). From ego depletion to vitality: Theory and findings concerning the facilitation of energy available to the self. Social and Personality Psychology Compass, 2, 702-717. doi: 10.1111/j.1751-9004-2008-00098.x

Sansone, C., \& Thoman, D. B. (2005). Interest as the missing motivator in self-regulation. European Psychologist, 10(3), 175- 186. doi: 10.1027/1016-9040.10.3.175

Sansone, C., Thoman, D. B., \& Smith, J. L. (2010). Interest and self-regulation: Understanding individual variability in choices, efforts, and persistence over time. In R. Hoyle (Ed.) Handbook of personality and self-regulation (pp. 192-217). Malden, MA: Blackwell.

Sansone, C., Wiebe, D. J., \& Morgan, C. L. (1999). Self-regulating motivation: The moderating role of hardiness and conscientiousness. Journal of Personality, 67, 701-733. doi: 10.1111/1467-6494.00070 
Sansone, C., Smith, J. L., Thoman, D. B., \& MacNamara, A. (2010). Regulating goals-defined and experience-defined motivation when learning online: Motivation and performance tradeoffs. Manuscript in preparation.

Sansone, C., Weir, C., Harpster, L., \& Morgan, C. (1992). Once a boring task always a boring task?: Interest as a self-regulatory mechanism. Journal of Personality and Social Psychology, 63, 379-390. doi: 10.1037/0022-3514.63.3.379

Schiefele, U., Krapp, A., \& Winteler, A. (1992). Interest as a predictor of academic achievement: A meta-analysis of research. In K. A. Renninger, S. Hidi, \& A. Krapp (Eds.), The role of interest in learning and development (pp. 183-212). Hillsdale, NJ: Erlbaum.

Schmeichel, B. J., Vohs, K. D., \& Baumeister, R. F. (2003). Intellectual performance and ego depletion: Role of the self in logical reasoning and other information processing. Journal of Personality and Social Psychology, 85, 33-46. doi: 10.1037/0022-3514.85.1.33

Shirey, L. L, \& Reynolds, R. E. (1988). Effect of interest on attention and learning. Journal of Educational Psychology, 80, 159-166. doi: 10.1037/0022-0663.80.2.159

Silvia, P. J. (2005). What is interesting? Exploring the appraisal structure of interest. Emotion, 5, 89-102.

Silvia, P. J. (2006). Exploring the psychology of interest. Oxford University Press.

Silvia, P. J. (2008). Interest—The curious emotion. Current Directions in Psychological Science, 17, 57-60. doi: 10.1111/j.1467-8721.2008.00548.x

Silvia, P. J. (2010). Confusion and interest: The role of knowledge emotions in aesthetic experience. Psychology of Aesthetics, Creativity, and the Arts, 4, 75-80.

Smith, J. L., Sansone, C., \& White, P. H. (2007). The stereotyped task engagement process: The role of interest and achievement motivation. Journal of Educational Psychology, 99, 99114. doi: 10.1037/0022-0663.99.1.99

Smith, J. L., Wagaman, J., \& Handley, I. M. (2009). Keeping it dull or making it fun: Motivational implications of regulatory focus. Motivation and Emotion, 33, 150-160. doi: 10.1007/s11031-008-9118-9

Thayer, R. E. (1989). The biopsychology of mood and arousal. New York: NY: Oxford University Press.

Thoman, D. B., \& Sansone, C. (2010). Getting different feedback for similar work: How benefiting from or being hurt by biased feedback affects activity interest and future motivation. Manuscript under review. 
Tice, D. M., Baumeister, R. F., Shmueli, D. \& Muraven, M. (2007). Restoring the self: Positive affect helps improve self-regulation following ego-depletion. Journal of Experimental Social Psychology, 43, 379-384. doi: 10.1016/j.jesp.2006.05.007

Tomkins, S. S. (1962). Affect, imagery, consciousness: Vol. 1. The positive affects. New York: Springer.

Turner, S. A., Jr., \& Silvia, P. J. (2006). Must interesting things be pleasant? A test of competing appraisal structures. Emotion, 6, 670-674.

Watson, D., Clark, L. A., \& Tellegen, A. (1988). Development and validation of brief measures of positive and negative affect: The PANAS scales. Journal of Personality and Social Psychology, 54, 1063-1070. doi: 10.1037/0022-3514.54.6.1063

Zemack-Rugar, Y., Bettman, J. R., \& Fitzsimons, G. J. (2007). The effects of nonconsciously priming emotion concepts on behavior. Journal of Personality and Social Psychology, 93, 927-939. doi: 10.1037/0022-3514.93.6.927. 